\title{
Lymphoplasmacyte-Rich Meningioma
}

National Cancer Institute

\section{Source}

National Cancer Institute. Lymphoplasmacyte-Rich Meningioma. NCI Thesaurus. Code C4720.

A WHO grade I meningioma characterized by the presence of prominent chronic inflammatory infiltrates that predominate over the meningioma cells. 